Asian J. Med. Biol. Res. 2020, 6 (1), 38-43; doi: 10.3329/ajmbr.v6i1.46477

\author{
Asian Journal of \\ Medical and Biological Research \\ ISSN 2411-4472 (Print) 2412-5571 (Online) \\ www.ebupress.com/journal/ajmbr
}

\title{
Article \\ Occupational hazards and health care seeking behavior of fishermen
}

Mohammad Abdulla Al Noman', Tarana Sharmin², Fatema Kabir Shoshi², Sanjida², Kanij Fatima Anee², Md. Belal Hossain ${ }^{3}$, Md. Nazrul Islam ${ }^{4 *}$ and Md. Shafiqul Islam Khan ${ }^{3}$

${ }^{1}$ Department of Food Technology and Engineering, Faculty of Nutrition and Food Science, Patuakhali Science and Technology University, Dumki, Patuakhali-8602, Bangladesh

${ }^{2}$ Faculty of Nutrition and Food Science, Patuakhali Science and Technology University, Dumki, Patuakhali8602, Bangladesh

${ }^{3}$ Department of Food Microbiology, Faculty of Nutrition and Food Science, Patuakhali Science and Technology University, Dumki, Patuakhali-8602, Bangladesh

${ }^{4}$ Department of Post-Harvest Technology and Marketing, Faculty of Nutrition and Food Science, Patuakhali Science and Technology University, Dumki, Patuakhali-8602, Bangladesh

*Corresponding author: Md. Nazrul Islam, Lecturer, Department of Post-Harvest Technology and Marketing, Faculty of Nutrition and Food Science, Patuakhali Science and Technology University, Dumki, Patuakhali8602, Bangladesh. E-mail: nazrul@ pstu.ac.bd

Received: 02 February 2020/Accepted: 12 March 2020/ Published: 31 March 2020

\begin{abstract}
About millions of households depend on fishing for livelihood though it is associated with different types of hazards. Working time does not allow fishermen to get health care for hazards from facilities. Data on occupational hazards and health care seeking is inconclusive in Bangladesh. This study was undertaken to assess the occupational hazards, associated factors and health seeking of fisherman. A cross sectional study involving 300 fishermen conducted from some selected communities of Patuakhali and Vhola districts from January to June, 2018. A pretested questionnaire used to collect information on socio-demography, occupational detail, types of hazards and health seeking behavior of fishermen. The results revealed that 69 faced different occupational problems during last 6 months. Participants suffered mainly from skin disease (31.7\%), musculoskeletal pain $(29.7 \%)$ and fever $(24.3 \%)$. Age and duration of profession identified were associated $(\mathrm{P}=$ $<.001)$ with occupational hazards. Only $7.3 \%$ respondents went to facilities to get health care. Nearly one-third of fishermen $(31 \%)$ took medicine by their own idea. Fishermen who seek care from facilities are low than affected with health hazards. Establishing facilities near major fish landings may improve health care seeking in this study area.
\end{abstract}

Keywords: occupational hazards; health-seeking; fishermen; Bangladesh

\section{Introduction}

Globally, fisheries support the livelihoods of over half billion peoples (Mandal et al., 2017). It provides nutrition, employment, export and food security (Rahman and Schmidlin 2014; Choo et al., 2015). But, fishing is with the high risk of hazards especially traumatic injury (El- Saadawy et al., 2014). Its global fatality is 80 per 100,000 (Mandal et al., 2017). Its rate is increased for the unsafe working environment (Jelewska et al., 2012). In coastal Bangladesh, about 484,000 households depend on fishing. Near about 12 billion people directly or indirectly depend on fisheries for their income (Mandal et al., 2017). But data on hazards of the fisherman is still unclear in Bangladesh. Fisherman suffers from different physical and psychological stress (Jelewska et al., 2012).

Previous study shown $75 \%$ fisherman feel musculoskeletal problem and $80 \%$ fisherman exposed to accidents during fishing in Bangladesh (Mandel et al., 2017). Fishing is one of the most important economic activities in 
the coastal area of Bangladesh. But it is hypothesized that fisherman in this area might suffer from a high prevalence of health problem but not reported until fatal. Also, some draw backing factors might be associated to get the hazards.

Health or care seeking behavior has been defined as any action undertaken by individuals who perceive them to have a health problem or to be ill for the purpose of finding an appropriate remedy (Oberoi et al., 2016). In Bangladesh, $47 \%$ of the seek people in a rural community sought treatment and rest did not go to health facilities. Since fishermen stay in water for long time the rate of health seeking behavior may be lower than others. We need a clear understanding of occupational hazards and predicting factors of fisherman. The baseline data may contribute to design and implement interventions against future hazards in the study area. The main objective of this study is to explore the health problems and care seeking behavior of fishermen.

\section{Materials and Methods}

\subsection{Study areas}

We conducted this study in Dumki and Golachipa, sub-districts of Patuakhali and Dualatkhan sub-district of Bhola. These three areas were faced river erosion due to vicinity or rivers. Many people of those three subdistricts depend on fishing. Those sub-districts has total population are 70,655, 361518 and 168537 (Dumki, Golachipa and Dualatkhan) where 447, 37000 and 19716 peoples are fishermen respectively (BBS, 2010-11).

\subsection{Study procedure}

This cross-sectional study investigated the occupational hazards and health care seeking activities of fisherman from July to December, 2018. Investigators visited at the household level and randomly selected 300 respondents for this study. Data was collected by face to face interview using pre-structured questionnaire. Respondents not present at survey time or unwilling to response not included in this study. We only considered those who spend up to five days in river for single trip.

\subsection{Data and variables}

We collected demographic (age, sex, ethnicity, educational qualification, marital status, family size, family income etc.), occupational (secondary occupation, reason to join fishing, types of boat, location, time of fishing and occupational accident), behavior like smoking history and types of hazards (disease or symptoms faced within last 6 months) for this study. Health seeking behavior of the respondent was also collected.

\subsection{Statistical analysis}

Frequency distributions and descriptive statistics for major demographic variables were computed. We used SPSS version 16.0 to analyze the data where P-values were $(\leq 0.05)$ considered statistically significant.

\section{Results}

According to field survey, the demographic data of this study reveals that among 300 respondents most peoples $(63.3 \%)$ are middle aged (>25). About $43.3 \%$ of the total respondents are from Dumki, $33.3 \%$ and $23.3 \%$ from Golachipa and Doulatkhan respectively. According to the view of religion and marital status, respondents are mostly muslim (67.7\%) and married (82.3\%). The educational qualification of the study areas people are; primary passed (55.7\%), secondary (12.3\%), higher secondary (0.3\%) and the rest are illiterate (31.7\%). Among all of the respondents about $26.3 \%$ are exist in monogamy family (1-4 members) and $73.7 \%$ are polygamy family (more than 4 members). The mean family income was 14340 tk. (median, 15040 tk.).

The following Table 1 shows that maximum fishermen are associated with fishing to survive their livelihood (78.3\%) and people involved in another occupation are $21.7 \%$. About half of the respondents are used large boat to catch fish. Two-third people of the fisherman use their own net. Almost all of the fisherman catch fish on river $(72.3 \%)$. The maximum fisherman catches fish both day and night. There are large numbers of people (78.0\%) faces occupational accident due to fishing. A few numbers of fishermen have fishing license and have no technical training about fishing. Rainy season is the most favorable time for fishing as per $97.7 \%$ respondents. Maximum numbers of fisherman are addicted to smoking (88\%). 
Asian J. Med. Biol. Res. 2020, 6 (1)

Table 1. Occupational details of fisherman in some selected communities of Patuakhali and Vhola, Bangladesh, $2018(\mathrm{~N}=300)$.

\begin{tabular}{|c|c|c|}
\hline Parameter & Frequency & $\%$ \\
\hline \multicolumn{3}{|l|}{ Another Occupation } \\
\hline Yes & 65 & 21.7 \\
\hline No & 235 & 78.3 \\
\hline \multicolumn{3}{|l|}{ Reason of fishing } \\
\hline Traditional & 197 & 65.7 \\
\hline Poverty & 64 & 21.3 \\
\hline Unemployment & 39 & 13.0 \\
\hline \multicolumn{3}{|c|}{ Days of Joining Fishing } \\
\hline $0.6-10$ & 200 & 66.7 \\
\hline$>=11$ & 100 & 33.3 \\
\hline \multicolumn{3}{|l|}{ Working member } \\
\hline$<=2$ & 138 & 46 \\
\hline $3<=$ & 162 & 54 \\
\hline \multicolumn{3}{|l|}{ Types of Boat } \\
\hline Dinggi (small boat) & 101 & 33.7 \\
\hline Large boat & 129 & 43.0 \\
\hline Taller & 70 & 23.3 \\
\hline \multicolumn{3}{|l|}{ Net Owner } \\
\hline Owned & 188 & 62.7 \\
\hline Borrowed & 112 & 37.3 \\
\hline \multicolumn{3}{|l|}{ Fishing Location } \\
\hline Sea & 83 & 27.7 \\
\hline River & 217 & 72.3 \\
\hline \multicolumn{3}{|l|}{ Spend time in Fishing } \\
\hline Daily & 293 & 97.7 \\
\hline $2-5$ days & 7 & 2.3 \\
\hline \multicolumn{3}{|l|}{ Fishing shift } \\
\hline Day & 83 & 27.7 \\
\hline Night & 83 & 27.7 \\
\hline Both & 134 & 44.7 \\
\hline \multicolumn{3}{|c|}{ Occupational Accident } \\
\hline Yes & 234 & 78.0 \\
\hline No & 66 & 22.0 \\
\hline \multicolumn{3}{|l|}{ Have License } \\
\hline Yes & 29 & 9.7 \\
\hline No & 271 & 90.3 \\
\hline \multicolumn{3}{|l|}{ Have Training } \\
\hline Yes & 9 & 3.0 \\
\hline No & 291 & 97.0 \\
\hline \multicolumn{3}{|l|}{ Favorable Season } \\
\hline Summer & 4 & 1.3 \\
\hline Winter & 3 & 1.0 \\
\hline Rainy Season & 293 & 97.7 \\
\hline \multicolumn{3}{|l|}{ Seller } \\
\hline Self & 189 & 63.0 \\
\hline Holder & 111 & 37.0 \\
\hline \multicolumn{3}{|l|}{ Leftover Food } \\
\hline Yes & 205 & 68.3 \\
\hline \multirow{2}{*}{\multicolumn{3}{|c|}{ Type of Drinking Water }} \\
\hline & & \\
\hline River & 119 & 39.7 \\
\hline Tube-well & 180 & 60.0 \\
\hline Others & 1 & 0.3 \\
\hline \multicolumn{3}{|l|}{ Dry Food } \\
\hline Yes & 242 & 80.7 \\
\hline No & 58 & 19.3 \\
\hline
\end{tabular}


The following Table 2 shows the disease related data of our selected areas fishermen. They are unconscious to take regular preventive visit and the percentage is $98.8 \%$. During the survey we found that around $69.3 \%$ of the total fishermen were suffered from many diseases in last 3-6 months (mostly skin disease, fever, musculoskeletal problem and diarrhea etc.). The percentages of specific diseases that the respondents suffered are skin disease (31.7\%), musculoskeletal problem (29.7\%), fever (24.3\%), diarrhea (17.7\%) and injury (16.3\%) respectively.

Table 2. Occupational hazards of the respondents.

\begin{tabular}{lll}
\hline Parameter & Frequency & \% \\
\hline Disease within Last 3-6 Month & & \\
Yes & 208 & 69.3 \\
No & 92 & 30.7 \\
Skin Disease & & \\
Yes & 95 & 31.7 \\
No & 205 & 68.3 \\
Respiratory Problem & & \\
Yes & 26 & 8.7 \\
No & 274 & 91.3 \\
Injury & & \\
Yes & 49 & 16.3 \\
No & 251 & 83.7 \\
Fever & & \\
Yes & 73 & 24.3 \\
No & 227 & 75.7 \\
Diarrhea & & \\
Yes & 53 & 17.7 \\
No & 247 & 82.3 \\
Scares From Cuts or Injury & & \\
Yes & 14 & 4.7 \\
No & 286 & 95.3 \\
Hepatitis & & \\
Yes & 5 & 1.7 \\
No & 295 & 98.3 \\
Musculoskeletal Problem & & \\
Yes & 89 & 29.7 \\
No & 211 & 70.3 \\
Other Diseases & 11 & 3.7 \\
Allergy & 11 & \\
Headache & & \\
\hline & & \\
\hline
\end{tabular}

After completion of taken field data, we have realized that maximum respondent's didn't take prescription from doctor until they face any severe diseases. The following Table 3 shows that the percentage of first time visits to doctor are higher (28.7\%) than second time visit (3.3\%). There are maximum fishermen like to visit local doctor $(12 \%)$ and nearest pharmacy (10\%) than registered doctor $(0.3 \%)$ and govt. hospital (7\%) for their diseases. About $5.7 \%$ fishermen visit doctor only for diarrheal cause. 
Table 3. Health care seeking behavior of the respondents.

\begin{tabular}{lll}
\hline Parameter & Frequency & \% \\
\hline Visit Doctor & 88 & 29.3 \\
Yes & 111 & 37.0 \\
No & & \\
No of visit & 86 & 28.7 \\
$1^{\text {st }}$ time visit & 10 & 3.3 \\
$2^{\text {nd }}$ time visit & & \\
Doctor Type & 21 & 7 \\
Govt. hospital & 1 & 0.3 \\
Registered doctor & 30 & 10 \\
Local Pharmacy & 36 & 12 \\
Village doctor & & \\
Causal disease to visit the doctor & 17 & 5.7 \\
Diarrhea & 13 & 4.3 \\
Skin disease & 12 & 4.0 \\
Fever & 11 & 3.7 \\
Musculoskeletal problem & & \\
Taken Medicine & 132 & 44 \\
Yes & 58 & 19.3 \\
No & & \\
Selecting Medicine From Own Idea & 93 & 31 \\
Yes & 81 & 27 \\
No & & \\
Prescribed Medicine & 80 & 26.7 \\
Yes & 93 & 31 \\
No & & \\
From whom advised medicine & 4 & 1.3 \\
Doctor & 5 & 1.7 \\
Govt. hospital & 17 & 5.7 \\
Local doctor & 54 & 18.0 \\
Pharmacist & & \\
\hline & &
\end{tabular}

Most of the fishermen take medicines by their own choice (31\%) and about $18 \%$ are taken medicines that are prescribed by a pharmacist. Correlation structure revealed that, age and duration of profession of fisherman inversely associate with the presence of diseases, skin diseases, respiratory problem and musculoskeletal pain. We can find from above this table the chance of having disease is inversely associated with age $(\mathrm{r}=-.333, \mathrm{p}=$ $.001) \&$ duration of professions $(\mathrm{r}=-.270, \mathrm{p}=.001)$. We can also find that age $(\mathrm{r}=-.253, \mathrm{p}=.001)$, educational qualification $(\mathrm{r}=-.236, \mathrm{p}=-.001)$ and duration of profession $(\mathrm{r}=-.240, \mathrm{p}=-.001)$ these three variables are also inversely associated with respiratory problems.

\section{Discussion}

Generally the fishermen are faced many diseases due to most of the time they stay in hazy and aquatic environment (Chauvin et al., 2017).We mainly conducted this study among the fisherman community who are live in the coastal area to identify occupational health hazards and their health seeking behavior. Fishing is a particularly dangerous profession with high risk of occupational and endemic diseases globally (Frantzeskou $e t$ al., 2012).

We found about $69.3 \%$ fishermen are faced many diseases within last 3-6 months at the time of data collection. Among the respondents, $31.7 \%$ fishermen were suffered from skin disease which is less than the study done among Moroccan fishermen (Laraqui et al., 2018). About $24.3 \%$ and $17.7 \%$ respondents suffered from fever and diarrhea which is less than the study was done in Boga fisherman (55\% and 30\% respectively) of Kachua upazila, Bagherhat district (Mandal et al., 2017). Compared to other diseases (allergies and headache), musculoskeletal problem (29.7\%) were crucial among the respondents but less severe than the previous study (ElSaadawy et al., 2014).

Due to fisherman occupation, they have to stay in the sea water for a long time which is not so easy to survive as land part. In the time of fishing they fell various occupational injuries. In this study about $78 \%$ people reported that they have faced in occupational accident where $49 \%$ have injured by cutting in their hand palm and finger 
as well as in feet, which is greater than the study done amongst Greece fishermen (Frantzeskou et al., 2012). Most of the hazard was occurred because of their inability and less sincerity about the use of protective tools. The study also shows that about $88 \%$ fishermen are addicted to smoking which is similar to another survey that conducted in Alexandria city of Egypt (El-Saadawy et al., 2014).

In Bangladesh, people with good education and economical background have visited healthcare facilities than uneducated and poor financial background (Chowdhury et al., 2007). According to the study result, most of the respondents were took primary education but they were less interested to take secondary and higher secondary education because of family responsibilities. That's why they were less sincere about their diseases and visit to healthcare facilities. Only $29.3 \%$ of total respondents took healthcare for their diseases where $7.3 \%$ visited to the registered doctor \& govt. hospital. There are about $10 \%$ and $12 \%$ respondents like to visit local pharmacy and village doctor respectively because of their easy accessibility.

Most of the fishermen (31\%) were like to take medicines as per their own choice. About $3 \%$ were taken the medicines as per registered doctors' advice and Govt. hospitals prescription but a higher percentage of fishermen were taken medicines that are suggested by the local pharmacist. As for preventive measure about $44 \%$ fishermen carried medicine (saline, Napa, gastric tablet etc.) during sailing.

In our study, cases were determined by participants themselves according to the definition of diseases, without biological or even practitioner's confirmation. We collected disease data within last 3-6 months in our survey that is different from other study survey in where disease data are collected in generally.

The study was not free from limitations. We had faced various limitations such as communication barrier to taken information from respondents, time matching with the respondents for interview etc.

\section{Conclusions}

Fishermen have to stay long time in the river for fishing and faces lots of hazards. Due to lack of time they did not get scope for health care. This study found that a significant number of fishermen face occupational problems but very neglected proportion visited to the registered doctor. The maximum fishermen did not take any training on their occupation. Proper awareness and training may reduce the hazards among the fishermen. They did not get health care from facilities as busy for whole day. The authorities should established proper health care facilities near fish landing areas to make them access to health facilities.

\section{Conflict of interest}

None to declare.

\section{References}

Bangladesh Bureau of Statistics (BBS), 2011. Statistical Yearbook of Bangladesh $31^{\text {st }}$ Edition.

Choo MKK, N El-Bassel, PCG Adam, L Gilbert, E Wu and BS West, 2015. Prevalence and correlates of HIV and Hepatitis $\mathrm{C}$ virus infections and risk behaviors among Malaysian fishermen. PLoS ONE, 10: e0118422.

Chowdhury RI, MA Islam, J Gulshan and N Chakraborty, 2007. Delivery complications and healthcare-seeking behaviour: the Bangladesh demographic health survey, 1999-2000. Health Soc Care Community, 15: 254264.

Chauvin C, GL Bouar and S Lardjane , 2017. Analysis of occupational injuries in the sea fishing industry according to the type of fishery and the fishing activity. Int. Marit. Health, 68: 31-38.

Frantzeskou E, AN Kastania, E Riza, OC Jensen and A Linos, 2012. Risk factors for fishermen's health and safety in Greece. Int. Marit. Health, 63: 155-161.

ME El-Saadawy, NE Soliman, IMM El-Tayeb and MA Hammouda, 2014. Some occupational hazards among fisherman in Alexandria city. Gaziantep Med. J., 20: 71-78.

Mandal S, I Hasan, NH Hawlader, I Sultana, MM Rahman and MSI Majumder, 2017. Occupational Health Hazard and Safety Assessment of Fishermen Community in Coastal Zone of Bangladesh. International Journal of Health Economics and Policy, 2: 63-71.

Jelewska M, MG Nowak, I Leszczyñska and B Jaremin, 2012. Occupational hazards for fisherman in the workplace in Polish coastal and beach fishing. Int. Marit. Health, 63: 40-48 .

Oberoi S, N Chaudhary, S Patnaik, and A Singh, 2016. Understanding health seeking behavior. J. Family Med. Prim. Care, 5: 463-464.

Laraqui O, N Manar, S Laraqui, T Ghailan, F Deschamps, R Hammouda and CEH Laraqui, 2018. Prevalence of skin diseases amongst Moroccan fisherman. Int. Marit. Health, 69: 22-27.

Rahman MK and TW Schmidlin, 2014. The perception and of natural hazards on fishing communities of Kutubdia island, Bangladesh, Geographical Review, 104: 71-86. 